\title{
"Queria ser uma travesti de respeito": processos de construções identitárias e subjetivas de mulheres trans e travestis na Microrregião do Seridó Oriental paraibano ${ }^{1}$
}

\author{
"Quería ser una travesti respetuosa": identidad y construcción subjetiva \\ de mujeres trans y travestis en la Microrregión Oriental Paraíba Seridó
}

\author{
"I wanted to be a respectful transvestite": process of identity and \\ subjective construction of trans and transvestite women in the Paraíba \\ Seridó Oriental Microregion
}

\author{
Jerferson Joyly dos Santos Medeiros ${ }^{2}$
}

\begin{abstract}
Resumo
O presente artigo tem como objetivo destacar os processos de construções identitárias e subjetivas de mulheres trans e travestis por intermédio de suas trajetórias de vida, tendo como marcadores sociais de gênero, sexualidade, geração, classe e raça em contextos do espaço familiar na efetivação do processo de transitividade do gênero. Ao longo do texto, estive traçando questões e investigando como as interlocutoras ilustravam seus processos de subjetividade em paralelos de ideias, representações dentro do binarismo de gênero. Tratou-se de uma pesquisa etnográfica realizada na Mesorregião da Borborema, tendo como foco a Microrregião do Seridó Oriental paraibano, geograficamente situada no Nordeste brasileiro. Na referida localidade composta por nove administrações políticas, detive-me a entrevistar interlocutoras das cidades de Cubati (7.234 hab.), Pedra Lavrada (7.475 hab.) e São Vicente do Seridó (10.775 hab.). Essa pesquisa faz parte do meu projeto de doutoramento que tensiona pensar trajetórias de vidas trans nessa microrregião. Como principais resultados, pude perceber como esses corpos ainda estão relegados às redes do patriarcalismo, embora em ambientes familiares diversos, e de que maneira as políticas públicas e de assistencialismo adotadas pelo Estado brasileiro para as pessoas trans ainda são insuficientes, pois são conduzidas, basicamente, em torno do respeito ao nome social, e a campanhas oferecidas pelo Sistema Único de Saúde no tocante ao tratamento de ISTs, HVI/AIDS, hormonioterapias e o processo transexualizador.
\end{abstract}

Palavras-Chave: trajetórias de vida; construção identitárias e subjetivas; mulheres trans; travestis.

\section{Resumen}

Este artículo tiene como objetivo resaltar los procesos de identidad y construcción subjetiva de las mujeres trans y travestis a través de sus trayectorias de vida, teniendo como marcadores sociales de género, sexualidad, generación, clase y raza en contextos del espacio familiar en la realización del proceso. de transitividad del género. A lo largo del texto, he estado haciendo preguntas e investigando cómo los interlocutores ilustraron sus procesos de subjetividad en paralelo con ideas, representaciones dentro del binarismo de género. Fue una investigación etnográfica realizada en la Mesorregión de Borborema, centrada en la Microrregión del Seridó Oriental de Paraíba, ubicada geográficamente en el noreste de Brasil. En la localidad mencionada compuesta por nueve administraciones políticas, me detuve para entrevistar a interlocutores de las ciudades de Cubati (7.234

\footnotetext{
1 Artigo apresentado no II Congresso Internacional Online de Estudos sobre Culturas, na modalidade online, 2019.

${ }^{2}$ Doutorando pela Universidade Estadual do Ceará - UECE; Fortaleza, Ceará, Brasil; joyly @uol.com.br.
} 
habitantes), Pedra Lavrada (7.475 habitantes) y São Vicente do Seridó (10.775 habitantes). Esta investigación es parte de mi proyecto de doctorado que tiende a pensar en las trayectorias de las vidas trans en esta microrregión. Como resultados principales, pude ver cómo estos cuerpos todavía están relegados a las redes de patriarcado, aunque en diferentes entornos familiares, y cómo las políticas públicas y de bienestar adoptadas por el Estado brasileño para las personas trans aún son insuficientes, ya que básicamente se llevan a cabo, en torno al respeto por el nombre social y las campañas ofrecidas por el Sistema Único de Salud con respecto al tratamiento de las ITS, HVI / SIDA, terapias hormonales y el proceso de transexualización.

Palabras claves: trayectorias de vida; identidad y construcción subjetiva; mujeres trans; travestis

\begin{abstract}
This article aims to highlight the processes of identity and subjective construction of trans and transvestite women through their life trajectories, having as social markers of gender, sexuality, generation, class and race in contexts of the family space in the realization of the process of transitivity of the genre. Throughout the text, I have been asking questions and investigating how the interlocutors illustrated their subjectivity processes in parallel of ideas, representations within gender binarism. It was an ethnographic research conducted in the Mesoregion of Borborema, focusing on the Microregion of the Seridó Oriental of Paraíba, geographically located in the Northeast of Brazil. In the aforementioned locality composed of nine political administrations, I stopped to interview interlocutors from the cities of Cubati (7,234 inhabitants), Pedra Lavrada (7,475 inhabitants) and São Vicente do Seridó (10,775 inhabitants). This research is part of my $\mathrm{PhD}$ project that tends to think about trajectories of trans lives in this micro-region. As main results, I could see how these bodies are still relegated to the networks of patriarchy, although in different family environments, and how the public and welfare policies adopted by the Brazilian State for trans people are still insufficient, as they are basically conducted, around respect for the social name, and campaigns offered by the Unified Health System regarding the treatment of STIs, HVI / AIDS, hormone therapies and the transsexualizing process.
\end{abstract}

Keywords: life trajectories; identity and subjective construction; trans women; transvestites.

\title{
1. Introdução
}

Nos últimos anos, o Estado brasileiro tem evidenciado algumas preocupações, embora sejam mínimas, em relação à população LGBTI+. Tais questões são ligadas a demandas Organização das Nações Unidas no Brasil, do movimentos sociais, do ativismo e de ONGs que vem levantando campanhas mundiais para promover a igualdade de Lésbicas, Gays, Bissexuais, Travestis, Transexuais, Intersexos e “+” para pessoas não-cis e que não se consideram trans. Dentro do crescente silenciamento do Estado, as articulações dos movimentos e do ativismo pela diversidade sexual tem sido de extrema primazia para fortalecer os mecanismo de luta e defesa no enfrentamento das LGBTIfobias, assim como na elaboração de politicas públicas mais efetivas em favor das comunidades e dos programas assistenciais. Entretanto, sabemos que a violência no Brasil tem corpo, cor e endereço, e que, para o Estado, as siglas parecem referenciar pessoas que ocupam os mesmos lugares e as mesmas hierarquias socioeconômicas.

O artigo aqui propõe observar marcadores sociais da diferença que são interseccionados por gênero, sexo, sexualidade, geração, raça e classe no tocante à diferença 
de gênero corporificada e a seus alcances nos contextos familiares, e como isso refletiu na insuficiência das politicas públicas do Estado por intermédio de trajetórias de vida de mulheres trans e travestis que vivem na Microrregião do Seridó Oriental paraibano, geograficamente situada no Nordeste brasileiro, levando em consideração três cidades que compõem a microrregião: Cubati (7.234 hab.), Pedra Lavrada (7.475 hab.), e São Vicente do Seridó (10.775 hab.). Trata-se de um recorte da minha pesquisa de tese doutoral que tenta articular os aspectos relacionados ao processo de construção de identidades de gênero, sentimentos de identificação e pertencimento, por intermédio de trajetórias de vida de mulheres trans e travestis. A referida tese é orientada pelo Prof. Dr. Roberto Marques, vinculado ao Programa de Pós-graduação em Sociologia da Universidade Estadual do Ceará UECE.

As três cidades, as quais me referencio ao longo do texto são cobertas por solos rasos de baixa fertilidade, sendo caracterizadas pela vegetação da Caatinga, assim como toda a microrregião. Os problemas básicos vão da escassez e da irregularidade de chuvas à falta de projetos municipais para capitação de água. As grandes estiagens prolongadas refletem diretamente na economia, tendo em vista que as atividades agrícolas e pecuárias são fontes de subsistência de uma parte das populações. Outra parte está ligada ao ramo da mineração: as três cidades são ricas em minerais, tais como xelita, quartzo, berilo, caulim, calcário, calcedônia, mica, barita, feldspato e tantalita.

A cidade de Pedra Lavrada, no ano 2000, recebeu beneficiamento de feldspato e quartzo do grupo cerâmico Elizabeth. Logo após, outras empresas foram se instalando: Mineração Florentino, Bentonit União, Mineração Seridó Ltda, Mineração Nossa Senhora da Luz e a MPL, Mineração Pedra Lavrada - PB Ltda, entre outras, sempre voltadas para a retirada dos recursos minerais, concentrando as atividades no processo de fabricação de cerâmicas, cosméticos, massas corridas, porcelanatos, revestimentos cerâmicos, pisos, tintas, vidros, areia higiênica para gatos, etc. Na cidade de Cubati, encontramos o grupo GMINEX Minérios Industriais que, desde 2007, também concentra suas atividades em tais processos. Pude notar que tais investimentos, nessas cidades consideradas interioranas, fazem parte de uma politica de economia capitalista global produtiva, assegurando que a identidade de um lugar surge da interseção entre seu envolvimento especifico em um sistema de espaços hierarquicamente organizados e sua construção como comunidade/localidade (GUPTA; FERGUSON, 2000). 
Nesse multiverso trans ${ }^{3}$, as trajetórias estão ligadas a um entendimento do binarismo de gênero. A transexualidade só deixou de ser oficialmente considerada doença em 18 de julho de 2018, quando a Organização Mundial de Saúde abandonou a ideia de "transtorno de personalidade e comportamento de identidade de gênero" e passou a entender tal expressão como "condições relacionadas à saúde sexual", classificando-a como "incongruência de gênero" (DSM-V; CID-11). Nessa nova classificação, a incongruência tem de ser "acentuada" e "persistente" nas atribuições experienciadas pelo gênero do sujeito que fuja daquele atribuído em seu nascimento. Os debates ainda precisam de um melhor entendimento e adaptações, tendo em vista que o "diagnóstico" além de não ser realizado antes da puberdade, segue uma linha de reforço às ideias cis-hetero-sexistas. Cada país tem até 1 de Janeiro de 2022 para incorporar a nova CID-11.

No Brasil, as politicas públicas permeadas pelo Sistema Único de Saúde são voltadas para "condutas heteroafirmativas". Para as comunidades LGBTI+ existem apenas programas de controle das ISTs e das pessoas convivendo com HVI/AIDS. Especificamente para as travestis e mulheres trans resta as hormonioterapias e o processo de readequação de sexo e gênero, o chamado processo transexualizador. Tal ação tem aumentado o número de procedimentos hospitalares e ambulatoriais, incluindo procedimentos de readequação sexual do gênero feminino para o masculino.

Os serviços são gratuitos, porém, na grande maioria das vezes, são insatisfatórios e inábeis, faltando capacitações e empatia por parte dos profissionais responsáveis, mesmo sendo em centros de referências. O Sistema Único de Saúde - SUS amarga os efeitos de uma perversa politica de contingenciamento de despesas (SEFFNER; PARKER, 2016), além de tudo se somar ao esvaziamento público das discussões sobre gênero e sexualidade como efeito do avanço dos setores conservadores no poder público, que tendem a se fortalecer na atual conjuntura política (MORA; FRANCH; MAKSUD, RIOS, 2018). As trajetórias que narrarei aqui levam em consideração as especificidades da vida, o contexto familiar e as condições socioculturais das entrevistadas, identificando como a inabilidade do Estado em

\footnotetext{
${ }^{3}$ Utilizo "multiverso trans" a partir de Silvana de Souza Nascimento (2019), entendendo a expressão como um ambiente plural de produção transitiva de corpos, subjetividades e territorialidades que dependem de uma autoidentificação de pessoas como travestis, mulheres transexuais, pessoa trans, transformistas, transgeneristas, chicas trans, homens trans, entre outras categorias êmicas, que podem construir condições permanentes ou situações de ser e/ou de estar que envolvem investimentos corporais, sexuais, afetivos, econômicos e políticos que escapam aos binarismos de gênero e, ao mesmo tempo, replicam esse binarismo em modelos identitários e corporais almejados.

${ }^{4}$ Assim como informa Pelúcio (2007, p. 21), entendo como condutas heteroafirmativas aquelas que estão "[...] focalizadas na família nuclear, no sexo reprodutivo, na valorização da penetração pênis/vagina, na desaprovação do sexo para adolescentes e pessoas "em idade não reprodutiva", entre outros dispositivos reguladores que tendem a patologizar as relações que escapam a esse modelo".
} 
assegurar os preceitos básicos instituídos na Constituição Federal fez de tais indivíduos aparatos de sobrevivência constante na ligação direta dia as relações patriarcais com normativas heterocentradas e misóginas, reproduzindo ideias referências clássicas do domus latino e do oikos grego, fixando fortemente o que há de semelhante em histórias tão distintas, e construindo um mito dos tempos imemoriais da dominação familiar e sexual que atravessaria toda a antiguidade, a idade média e a moderna, chegando à contemporaneidade (MACHADO, 2000).

Nessa perspectiva, percebo uma falta no discurso do Estado brasileiro, um olhar interseccional sobre a questão aqui levantada, em que o universo masculino, em certo sentido, releva uma predominância de regras sociais que ainda separam tudo que foge à normatividade heterossexual, principalmente em espaços e lugares de um individualismo familiar ou de redes compartilhadas nas vivências cotidianas. Assim, não posso classificar esse multiverso trans como sendo categoria única e estática; cada indivíduo expressa o seu processo identitário de forma singular, dentro de uma diversidade de realidades e em diferentes contextos, em que a vida vai sendo exercida e experienciada. A teoria de base deste artigo vai ao encontro do conceito da diferença problematizado por Avtar Brah (2006, p. 371): "O conceito de diferença, então, se refere à variedade de maneiras como discursos específicos da diferença são constituídos, contestados, reproduzidos e ressignificados”. Tal conceito, de um lado, forma o sujeito de modo processual a partir de sua trajetória individual e específica e, de outro, produz narrativas históricas e culturais coletivas compartilhadas (NASCIMENTO, 2019).

Tendo como exemplos as narrativas das interlocutoras, pude perceber a similaridade de prática de estigmatização, inferiorização, exclusão e discriminação nos mais variados contextos que são exercidos pelo poder familiar. Na primeira instância, há a própria constituição corporal e de comportamentos que se ligava a uma feminilidade ${ }^{5}$; em segunda instância, há as formas simbólicas de exclusão no meio social; e, por último, há a articulação das vozes polifônicas das interlocutoras dialogadas em discursos plurissexuais baseados em estilos de vida.

\footnotetext{
${ }^{5}$ A corporeidade percebida neste artigo pautou-se nas ideias teórico-metodológicas de Thomas Csordas (2013). Para este autor, o corpo é a base existencial da cultura como ser-no-mundo, pois suas diversas maneiras de ser são construídas culturalmente, ao mesmo tempo em que produz sentidos particulares. Com efeito, a corporeidade é a nossa condição existencial fundamental, a nossa corporalidade (corporeality ou bodiliness) em relação ao mundo e às outras pessoas (CSORDAS, 2013). Assim, as técnicas corporais das interlocutoras borram as mimesis do caráter feminino, postulando molduras heterocentradas, de exclusões e antíteses.
} 
O artigo, dessa maneira, vai ao encontro de direcionamentos estruturados pelas entrevistas e conversas informais realizadas, levando os processos de construções identitárias por um aspecto: a autoafirmação da transitividade do gênero no espaço familiar. As interlocutoras, ao se questionarem sobre o que estavam acontecendo com seus corpos, se aqueles corpos eram realmente delas, se existiria outras maneiras de se verem, indagam sobre aceitações de alguns membros da família ou a ojeriza de outros, informam especificações da tentativa de se comunicar com a família biológica, dentro das relações que são construídas e dão sentidos às diferenças sexuais. Não sendo aceitas em seus âmbitos familiares, elas procuram outros núcleos familiares que as instituem e começam a perceber - por terem alguns auxílios negados - a ausência de mecanismos do próprio Estado na falta de auxilio e acompanhamento nos seus processos de autoidentificação.

\section{Travessias marcadas pelo poder do pai}

Carla é mulher trans preta, Mandy, mulher trans branca, e Suzi ${ }^{6}$, travesti branca; As três são reprodutoras de técnicas corporais de uma feminilidade heterossexual, de mimesis de um feminino que foi sendo desenvolvido enquanto observava as outras irmãs ou em seus deslocamentos fronteiriços. O sexo das três, atribuído ao nascimento, seguia a ordem binaria masculina, mas a percepção e a sensação que sentiam dos seus corpos fugiam daquela ordem. Elas têm um olhar diferente sobre o mundo e o seus corpos, e sabem do sentido que eles refletem nos lugares que passam. Quando as entrevistei, no período de julho a setembro de 2019, Carla tinha 40 anos, Mandy, 42 anos, e Suzi, 38 anos recém-completados, seguindo uma linearidade nas gerações e nos contextos de seus processos identificatórios corporais.

Carla é natural de Cubati, embora já tenha transitado por outras regiões do país. Ela enfatizou: “[...] não saio mais daqui; meu pai já me aceitou, e eu não tenho mais idade de ficar de um lugar para o outro. Já fiz meu curso de técnico de enfermagem e está bom”. Ela terminou o Ensino Médio aos 28 anos de idade na única escola estadual da cidade, por intermédio da Educação de Jovens e Adultos. Oriunda de classe popular, em seus relatos, ela fala como foi difícil conquistar o apoio da família e fazer o seu pai entender que ela era uma mulher como as suas outras irmãs:

\footnotetext{
${ }^{6}$ Nesse momento, preferi atribuir pseudônimos às pessoas envolvidas e às interlocutoras. Entretanto, as referências de pessoas, lugares e marcas que as entrevistadas citam ao longo de suas falas eu fiz questão de resguardar.
} 
Cidade pequena tem esse problema, no começo todos pensam que você é bicha pelos seus jeitos, só que tem as bichas e tem a gente que é mulher diferente das mulheres com vagina. Eu sou de uma geração que não existia esses nomes todos, mas eu entendia que era diferente. No começo eu pensei que era bicha mesmo, mas depois eu senti a necessidade de mudar meu corpo, queria ter peitos como minha irmã mais nova tinha. Eu venho de uma família de agricultores ${ }^{7}$. Tenho quatro irmãos, três mulheres, eu me incluo, e meu irmão, eu sou a mais nova. A infância foi um verdadeiro tormento, pois eu via minhas irmãs com aqueles vestidos floridos e bonitos e não podia usar. Uma vez, aos 14 anos, quando não aguentava mais guardar aquilo dentro de mim, peguei algumas roupas da minha irmã mais velha, e comecei a me vestir igual. Fiquei tão desajeitada, mas estava me sentindo linda. Coloquei até uma flor no cabelo [...] E nisso minhas irmãs foram me ajudando. O problema era papai e meu irmão. Mamãe sabia, sabia porque ela deixou de trazer roupas para mim e mandava eu escolher. Quando completei 16 anos, resolvi mudar de vez e contar a papai, não teve outra, você sabe, né? Esse povo mais antigo, homem demais, me deu logo uma surra e mandou eu ir embora de casa. Tia Cláudia já sabia, ai fui morar com ela.

Dois anos separavam as idades de Carla e Mandy. Esta última, natural de Pedra Lavrada, nunca saiu do seu município de origem a não ser para fazer suas viagens e para comprar acessórios para as lojas de conveniências que mantinha com a família há algum tempo: "Eu amo esse meu interiorzinho, foi aqui que eu me criei, e tive chance de ser alguém”. Mandy estudou na escola estadual do município e terminou seu Ensino Médio na educação regular com 16 anos. Logo após, ingressou na Faculdade de Administração da Universidade Federal de Campina Grande - PB, para onde ia todos os dias, retornando à sua cidade em um carro disponibilizado pela prefeitura municipal para alunas/os que estudavam no turno da noite. O tempo de Pedra Lavrada a Campina Grande é de mais ou menos 1h30mim, com uma distância de $101 \mathrm{~km}$, aproximadamente. A família da interlocutora era de classe média alta; com pai advogado e mãe professora de educação básica, ela era a mais velha de quatro irmãos, começando seu processo de transição ainda na adolescência:

Eu nunca aceitei meu corpo. Nunca. Ia para igreja e pedia a Deus para tirar aquela vontade que eu tinha de mudar, de ser outra pessoa. Eu tinha muitos jeitos femininos, e minha mãe e meu pai nunca recriminaram, alguns fatos esporádicos na infância, e no começo da adolescência, como mandar ajeitar a mão, ou descruzar as pernas. Mas como sempre fui muito comportada, estudiosa e sempre na minha, digo com poucas amizades, não tive que dá muita satisfação as pessoas quando tornei mulher de verdade. Eu me sentia muito diferente, e teve um episodio que me fez criar coragem para assumir a mulher que tinha dentro de mim. Minha mãe sempre

\footnotetext{
${ }^{7} \mathrm{Na}$ tese, faço uma maior abrangência nas teorias sobre as fronteiras do campo e da cidade nessas chamadas "cidades de pequeno porte", classificadas pelo IBGE como cidades de até cinquenta mil habitantes, levando em consideração os novos manejos de examinar o espaço interligado por outras fronteiras no olhar reflexivo da memoria histórica e da organização do social.
} 
comprava muitos produtos de beleza, e eu tinha muita vontade de usar, comentava com uma amiga especifica que tinha vontade de ficar maquiada. Um dia essa minha amiga me deu um batom de presente e fez eu passar. Meu mundo naquele momento caiu; me culpava por ter passado, mas tinha gostosa da sensação. Pedi segredo a ela. Mas esse foi só um passo, quando todo mundo saia, ou ficava só meu quarto pegava as maquiagens e as roupas da minha irmã e me fazia toda. Só que na época eu pensava que era homossexual, eu não entendia [...] Quando passei no vestibular conversei com meus pais, e disse que não sabia o que fazer, pois não aguentava mais me ver naquele jeito, com aquele cabelo, com aquelas roupas. Minha mãe começou a chorar e meu pai pediu tempo, e depois de alguns dias me levou a um psicólogo, e o processo começou ali.

Quando fiz a entrevista com Suzi, ela tinha acabado de chegar do Rio de Janeiro: "Vim para ficar, não aguentava mais aquele mundo faz de conta. Envelheci e preciso de um lugar mais fixo". A interlocutora nasceu em São Vicente do Seridó, mas, aos 13 anos, mudouse com a família para a capital João Pessoa, onde morou por 5 anos. Depois, acabou retornando à sua cidade de origem: "Papai tinha disso, ia para aventurar as coisas e se desse certo ficava, se não, voltava. Minha família é de classe média, meu pai vivia de agiotagem ${ }^{8}$, ele já faleceu, faz uns dois anos e minha mãe ainda mantém um salão de beleza com minha tia em João pessoa". E foi nessas idas e vindas que Suzi foi tomando consciência do seu corpo e das suas mudanças, como também tendo atrasos e evasões na vida escolar, por ajudar a mãe e a tia no salão, com suas duas irmãs. Acabou abandonando a escola e não concluiu o Ensino Fundamental II. Todavia, foi por intermédio das "ajudas esporádicas" que oferecia às parentes que começou o seu processo de reconhecimento e mudança:

Minha infância foi perfeita. Não tive problema nenhum. Brincava com minhas irmãs, tinha outros amigos, só que eu me sentia diferente, eu brincava com os meninos e gostava e brincava com as meninas e gostava também, só que eu gostava de pegar uma toalha e inventar que era meu cabelo, pintava minhas unhas escondias, mesmo que eu tirasse na mesma hora, eu não sei explicar, eu era criança e me divertia. Na época, nisso eu ainda morava em São Vicente e tenho uma lembrança muito viva, que saiu um boato de Seu Manoel, que era um vizinho nosso, muito amigo de papai, inclusive. Estava tendo um caso com Pachanca, na época a gente tirava resenhava que pachanca era bicha e mulherzinha, e eu lembro que ninguém queria ser vista com ela, mas eu me sentia parecida, só que não dizia nada a ninguém [...] Fui embora para João Pessoa e comecei a ajudar a mainha no salão, o salão ficava na Antônio Rabelo Júnior, quase no final. Nesse mundo de alisamentos, escovas e colorações, unhas pintadas, maquiagens fui me descobrindo, e me transformando. O mais engraçado que ninguém nunca lá de casa disse nada, só mandava eu ter cuidado e não levar homem para dentro de casa, só papai que se

\footnotetext{
${ }^{8}$ Achei pertinente colocar uma nota sobre a palavra, tendo em vista que ela pode ter variações internacionais. "Agiotagem" é a prática de emprestar dinheiro fora do mercado de crédito legítimo. Essa "tipo de empréstimo" é considerado crime contra a economia popular previsto na Lei $\mathrm{n}^{\circ} 1521 / 51$.
} 
fazia de despercebido. Cheguei a beijar algumas mulheres ainda e frequentar bares com minhas irmãs, antes de começar as mudanças, óbvio. Mas o divisor de águas foi quando Bianca chegou no salão para fazer uma progressiva, lembro como se fosse hoje. Muito bem vestida, cheirosa, peitos avantajados, cintura fina, e mamãe pediu para eu atendê-la. Eu só tinha o cabelo grande e utilizava algumas peças femininas, e usava o meu antigo nome. Quando peguei os produtos para começar a aplicação, ela perguntou a marca e disse que tivesse cuidado no couro cabeludo, pois a última vez que ela tinha feito o procedimento tinha sido na Europa e não tinha gostado muito, e ela era muito exigente, pois era uma travesti de respeito. Meu reconhecimento foi imediato, eu queria ser Bianca, e queira ser uma travesti respeito. Nisso, comecei o meu processo.

Os contextos familiares das interlocutoras marcam diferenças entre seus processos de deslocamentos e fronteiras no gênero, pois pude compreender que, em suas trajetórias, os momentos de ruptura do binarismo imposto culturalmente vêm acompanhados do processo de afirmação no âmbito familiar, sendo este um marco decisivo na construção subjetiva e identitária. Assim também percebi a importância da segregação familiar, menos de uma forma masculina do que um modo pelo qual as relações são construídas e dão sentido às diferenças sexuais (NASCIMENETO, 2012).

E foi a partir da problemática das subjetividades e do processo indenitário que compreendi a dinâmica de poder exercida pelos pais, que se associavam ao modelo patriarcal nas relações de gênero e nas condições de transitividade do gênero. Isso reforça a ideia de que existe uma organização "tradicional” de família que segue um plano heterocentrado, patriarcal e reprodutor de tal noção familiar, configurado como um núcleo único, sem entendimento e expansão das novas configurações de família: “[...] reduzindo-as a extensões de um núcleo homogêneo que não teria feito mais do que se expandir e progredir através do tempo e do espaço" (CORRÊA, 1994). Em todas as falas, fica perceptível que a ideia de afirmar suas técnicas corporais da transitividade do gênero e todos os medos imbricados nessa afirmação estavam relegados à ideia de uma ordem maior, uma ordem reguladora que definia o destino de corpos que não se enquadravam naquele mundo construído culturalmente.

As mães amparam suas filhas dentro desses contextos como sendo mais maleáveis e entendedoras, assim como as irmãs. Nessa dinâmica, posso inferir que as relações patriarcais uma forma especifica de relação ao gênero em que as mulheres estão numa posição subordinada (BRAH, 2006) dentro do núcleo familiar heterossexual - continuam a ser investidas com um olhar regulador e de exclusão do corpo feminino. Sendo mulheres cis, 
trans ou travestis, mas desde que reproduzam mimesis ${ }^{9}$ do feminino e que quebrem o binarismo de gênero, todas são colocadas sob um olhar de subordinação, obediência e exclusão. Nesse sentindo, a autoridade patriarcal se apresenta aos olhos dos outros sujeitos sociais como legítima. Os direitos sexuais naturais, paternal e masculino, só se sustentam pela naturalização da diferença sexual e da hierarquia da descendência (MACHADO, 2000), o que foi visto nas interlocutoras.

As trajetórias passam por momentos de diferenciações nas relações patriarcais. No entanto, como exemplifica Lia Machado (2000, p. 6): "Enquanto o conceito de gênero permite a interrogação de toda e qualquer formação cultural e social, o conceito de patriarcado se circunscreve a formas sociais que sejam definidas como tal e tende a aprisioná-las como totalidade neste único sentido". Mesmo as interlocutoras apresentando trajetos, fronteiras e deslocamentos diversos, elas ficam submetidas ao domínio patriarcal, no seu sentido sóciohistórico e teórico, mesmo configurando novos agentes da vida social.

$\mathrm{O}$ devir feminino ${ }^{10}$, quando se intersecciona à raça e à classe, cria uma estrutura maior de opressão. A expulsão imediata de Carla de sua casa mostra o seu enfretamento especifico em violências psicológicas, físicas e socioeconômicas. O seu pai contava com a ajuda dos seus dois "filhos homens" para o manejo das hortas e a venda na feira, que acontecia aos domingos. Quando Carla fala ao pai sobre sua transição, o descontentamento, a perca da honra $^{11}$ familiar e a vergonha perante a sociedade cubatiense traçava limites fixos sobre a estrutura de uma sociedade racista, machista e misógina.

O irmão passou a renegá-la, as piadas com a cor de sua pele intensificaram nos âmbitos que ela passou a transitar, e seu corpo passou por normativas que a excluíam de determinados lugares, sendo um deles a sua própria casa. Carla evidencia, por intermédio da sua classe, outros eixos de diferenciação como o racismo e a transfobia, observando seu corpo dentro de uma lógica de desigualdade, opressão, exploração: "Sempre era a nega gostosa do

\footnotetext{
${ }^{9}$ Vale salientar que a noção de mimesis adotada neste artigo vai de acordo com o uso de Michel Taussig (1993, p. XII): "The wonder of mimesis lies in the copy drawing on the character and power of the original, to the point whereby the representation may even assume that character and that power".

${ }^{10} \mathrm{O}$ devir feminino aqui entendido vai de acordo com a ideia explanada por Silvana Nascimento (2014, p. 387), que ensaia não pensar em identidades, mas em construção de pessoas na elaboração de um devir feminino dento do multiverso trans: "O devir feminino abarca aqui desde transexuais que se definem como mulheres, e que inclusive já realizaram mudança do nome social e possuem o reconhecimento jurídico da mudança de sexo, travestis que não querem realizar o processo cirúrgicos de transgenitalização (sic) - ainda que a questão de ter ou não pênis seja central para a elaboração da ideia de um feminino "perfeito".

${ }^{11}$ Pude entender a honra no sentido de reflexos das relações patriarcais em abordagens históricas e transculturais ligadas à violência, à humilhação e à vergonha. Trata-se de um assunto a se aprofundar, uma temática bastante visível dentro dessa transitividade em que o gênero se apresenta.
} 
cabelo alisado, a bichinha que dava para todo mundo". Como afirma Bell Hooks $(2005$, p. 7): “[...] cenas cotidianas nos aferem a condição de que não seremos bonitas e atraentes se não mudarmos a nós mesmas, especialmente nosso cabelo".

Ao ir morar com a tia, ela teve acolhimento e entendimento, embora tenha demostrando em momentos da entrevista o quanto foi forte ante seus conflitos internos, demonstrando o impacto disso em sua autoestima. Ao mesmo tempo em que passava por esse processo de transição de gênero, ela tentava seguir uma lógica de mimesis de mulheres brancas: "Eu chorava todo tempo, queria ser uma mulher branca, alisava meu cabelo, comparava maquiagens com tom de pele mais clara". A produção da subjetividade de pessoas trans e travestis pretas dentro dessas relações patriarcais passam e sofrem pelo processo de branquitude, as quais se apoiam, usam e elaboram as mesmas prerrogativas ambíguas e contraditórias do dispositivo de sexualidade fazendo parte da coisificação e da objetificação nas gramáticas do poder erótico. Embora a sociedade coloque inscrições no seu corpo, como "a nega gostosa", as conjecturas na vida da interlocutora passam por construções que ainda valorizam a brancura como marca e o padrão absoluto de normalidade. Nesse sentido, as Narrativas Mestras nos Estados Unidos e no Brasil postulam a classificação de negro como algo negativo a ser superado (GILLIAM, GILLIAM, 1995), fazendo com que muitas travestis e mulheres transexuais, para afirmarem suas identidades femininas, camuflam suas identidades negras (BRITO, 2016).

Mandy e Suzi conseguiram transitar em seus contextos familiares de forma menos danosa e dolorosa se comparados ao mundo de Carla. Ambas de classe média e brancas, elas tiveram seus privilégios, porém ainda foram relegadas de sofrimento simbólico com fronteiras de olhares, comportamentos, gestos e lugares. Na consulta com o psicólogo, Mandy confirma o que o seu corpo já sentia; o diagnóstico dado conforta a família e ela torna-se visível, porém os cuidados são redobrados: “[...] fiquei meses em casa, papai ia me deixar e buscar no ponto do ônibus, e eu ia com roupas mais masculinas para a universidade".

A rede acionada pela interlocutora demostra outras conjecturas com as relações patriarcais, pois a figura do pai é criada e cristalizada em moldes de uma sociedade heterossexual branca: um homem branco rico, casado, cristão, que defende a família e procura soluções rápidas para o não entendimento da filha sobre sua sexualidade: "Pai sempre se mostrou muito presente. Me deu total apoio e começou a me pedir para eu ter determinados tipos de comportamentos, como não sair muito de casa só, não ir as festas e deixar de frequentar a igreja, até hoje eu não vou". Tais aspectos pedidos à filha reforçam o mesmo medo de ter sua honra exposta por comportamentos da transitividade do gênero, causando um 
desarranjo no ambiente social da família. Esse comportamento está ligado ao poder simbólico masculino, ao modelo heterossexual normativo e constitutivo de relações de poder, assim como todos os dispositivos de sexualidade ao longo da história (FOUCAULT, 1982). Assim, o pai da interlocutora não descarta que ela possa viver em relações do tipo do mesmo sexo se seguisse os padrões impostos por ele e pela sociedade cisgênera.

Mandy sempre se sentiu muito amada por todos da família, embora a mãe evitasse ir a alguns lugares com ela: “[...] mãe não me levava para visitar vovô, dizia que era melhor assim, só fui visita-la quando ela adoeceu e estava no hospital, ela não me reconheceu". A mãe também sugeriu que ela fosse morar um tempo em Campina Grande, ideia derrubada pelo pai, que tinha medo da violência: "Eu entendia a preocupação da minha mãe em alguns aspectos, mas como a ordem final era sempre de papai, eu ficava esperando as coisas acontecerem". Embora a família aceitasse Mandy e a tivesse ajudado no processo de transição, ela foi impedida de viver aspectos comuns e corriqueiros das pessoas cisgêneras. Nesse sentindo, “[...] la clase social configura un entramado de aspectos económicos, políticos, culturales, étnicos, de género y cotidianos" (GARCÍA, 2018), fazendo com que corpos que fogem da normatividade heterocentrada, mas que usam de seus lugares de privilegio econômico, fixem-se em espaços com regras definidas e rígidas pela heterossexualidade de sujeições conceituais de um feminino cisgênero, com medo de sofrerem retaliações, discriminações e abandono da família e da sociedade de um modo geral.

Com Suzy, as relações patriarcais escaparam das bordas; o pai invizibilizou seu corpo, e só o trazia à tona quando precisava de alguma grana: “[...] papai era demais, nunca disse nada comigo, também não falava nada e nem olhava para minha cara. Nós almoços que fazíamos no domingo, me tratava como se fosse alguém conhecido". Só que as cobranças na casa da interlocutora começavam a chegar, e principalmente de pessoas de "mau-caráter"; era quando as configurações da persistência hegemônica de uma dominação masculina, enraizadas no social e no cultural legitimavam o poder do pai de Suzy: "Eu "emprestava" o dinheiro para ele, emprestava é uma palavra muito abrangente, você me entende, né? Eu ficava com pena e tinha medo de alguém fazer algumas coisa no salão, acabava dando o dinheiro todo para me livrar".

Nesse modelo, a identidade de Suzi aparecia para se vincular a um papel de fronteiras definidas e fixas de poder regulador no medo de que o pai fizesse alguma coisa contra ela, fazendo-a com que sofresse. A liberdade para ela é entendida no momento em que o pai "a deixa de lado", mas também "não diz nada", fazendo que a unidade familiar de Suzi seguisse as relações hierárquicas do parentesco. Esse tipo de situação e a de Mandy especificam as 
redes de sentido da construção dos gêneros e de suas relações, seguindo a agenda política de cada vez mais desnaturalizar a dominação derivada da diferença sexual (MACHADO, 2000). Tais redes são acionadas por intermédio da afetividade familiar e pelo medo da honra da sociedade Lavradense, ou por questões de poder aquisitivo.

Podemos pensar em dinâmicas com fluxos distintos, porém discutidos e representados em articulações à subjetividade, que é ponto fundamental. Ambas buscam manter um poder simbólico tradicional, com valores educacionais, políticos, socioculturais pautados numa tradição e em valores de condutas aceitáveis, heteronormativas. Nesse sentindo, os atributos de gênero não são expressivos da sua transitividade, mas de uma logica binária e performática, que impõe reencenação e nova experiência de um conjunto de significados já estabelecidos socialmente, também sendo a forma mundana e ritualizada de sua legitimação (BUTLER, 2003).

Carla, Mandy e Suzy replicam e reinventam as mimesis de um feminino patriarcalizado, acionando suas diferentes posições hierárquicas para performatizar atributos que destoem ou constroem uma sociedade heterossexual centrada no falo masculino. Elas representam tantas outras trajetórias de mulheres trans e travestis que, por medo, ojeriza ou repressão, aceitam lugares de monitoramento e de um poder regulador cisgênero. É notório que, em todas as falas, fatores como gênero, sexualidade, classe, geração e raça intersecionam e influenciam na relação familiar.

A relação com o gênero é apreendido na aproximação dos seus contextos e de politicas públicas que legitimam as diferenças e elaboram uma imagem mimética a partir de redes de acesso que são compartilhados pela sociedade em conjunto com a família, a igreja, as escolas, as ONGs, os movimentos e o próprio Estado. Todas as interlocutoras com as quais fiz as entrevistas e tive contato relataram sobre a falta de um mecanismo de amparo do Estado para a efetivação tanto no acolhimento no caso de expulsão de casa, como nos tratamentos que a rede de saúde disponibiliza para casos mais específicos desse multiverso: a hormonioterapia e o processo transexualizador, incluindo o tratamento de ISTs e HVI/AIDS.

Esses manejos são derivas básicas do direito sexual humano, mas que são tratados como algo inovador e, mesmo assim, sem muito respaldo nas formas de tratamento e entendimento da subjetividade. Esse multiverso trans sofre violências e vive uma grande precariedade cotidiana nas suas formas mais diversas, embora cobre uma maior proteção e cuidado na efetivação de politicas públicas. O Estado continua com os olhos vendados, mais ainda no momento em que estamos vivendo, de uma politica conservadora e de retirada de direitos básicos. 
Como já mencionei no começo do artigo, as politicas do Estado brasileiro ainda são ineficientes, pois refletem as dicotomias do sexo biológico e suas diferenciações de homem e mulher no desenvolvimento de politicas públicas para toda a população, pautadas em um constrangimento de padrões sexistas e heternormativos. Trata-se de um sistema precarizado, heterocentrado e com mecanismo de exclusão de corpos que fogem das normas binarias de gênero. A luta pelo reconhecimento e pela cidadania desse multiverso é uma meta que toda instância governamental deveria se engajar, pois, ao não ter acesso a algumas demandas de politicas públicas, comprovamos o que Tatiane, mulher trans branca, de 34 anos, classe popular, sua mãe dona de casa e pai minerador, residente em Pedra Lavrada, relatou quando a questionei sobre suas idas ao posto de saúde:

O desrespeito começa na porta, não sabem te tratar, não querem chamar você pelo nome social, te fazem de palhaça. Quando você fala sobre hormônios, eles dizem logo, vai para o Hospital Clementino Fraga ${ }^{12}$, precisa tirar ficha para o médico não, é só ir na assistência social que eles informam. Só ocupar a fila, porque o que ele vai dizer lá dentro, a gente aqui na recepção já sabe. Cidade pequena é assim, ou sua família aceita e mesmo você sofrendo um monte de desrespeito aceita, ou é rua e te vira.

\section{Considerações provisórias}

Ao trazer a ideia de como são construídos os processos identitários e subjetivos na autoafirmação da transitividade do gênero no espaço familiar, tentei reiterar que fatores como gênero, raça e classe, em contextos específicos, podem gerar apoio ou rejeição. E a figura do pai ainda é um fator predominante para ajudar nesse processo de autodescoberta. As trajetórias aqui narradas se abrigam dentro de contextos de organizações familiares especificas, embora fiquem subsumidas ao domínio das redes do sistema patriarcal. São experiências distintas, que reforçam a quebra no sistema que associou a dominação patriarcal ao homem de classe média e raça dominante, como a base da sociedade; as interlocutoras apresentam elementos que recriam e replicam toda essa rede. Tais trajetos aqui escritos representam uma pequena parte desse multiverso trans de experiências que desafiam, borram e reproduzem as ordens binarias do gênero e da sociedade heterocentrada.

Seguindo um fluxo de pesquisas que tensionam as cidades interioranas como foco de descentramentos e outras axialidades no campo da antropologia, propus uma ampliação de

\footnotetext{
${ }^{12}$ O Hospital se localiza na capital da Paraíba, na cidade de João Pessoa. Embora todas as mulheres trans e travestis sejam encaminhadas para o referido hospital, o processo feito é para hormonioterapia. O referido hospital não é habilitado para realizar as cirurgias de redesignação sexual. Transexuais que buscam o procedimento precisam passar por no mínimo dois anos de hormonização e entrar numa lista de espera em estados onde o procedimento já é realizado gratuitamente, a exemplo de Pernambuco, São Paulo e Paraná.
} 
novas questões no arcabouço teórico de tais temáticas e de como os estudos sobre gênero, sexo, sexualidade e processos interseccionais vão aos poucos borrando e descontruindo os processos coloniais dos eixos academicamente hegemônicos. Pois tais trajetórias mostram a resistência e o enfrentamento de vidas que são conjecturadas dentro de uma cisnormatividade do gênero, em paralelos de ultrapassar limites inacessíveis ao aparato de poder/saber/ser na gramatica social construída sobre seus corpos, fronteiras e descolamentos.

O Estado brasileiro, ao abordar as politicas públicas para esse multiverso trans, não adotou posturas especificas e nem interseccionais, não promoveu debates, conferências, fóruns, congressos que aproximassem pautas com a militância e o ativismo, que escutassem as vivências. A narrativa hegemônica sustentada a partir da transexualidade como doença apagou por muito tempo os lugares de enunciação desses corpos em transitividade do seu gênero, substituindo suas experiências identitárias e subjetivas por narrativas de patologização, descriminação, ojerizas, desrespeitos, mortes etc. Sendo disseminadas nas estruturas de poder que alocam as experiências travestis e trans no campo da (psico)patologia, destacam-se aquelas ligadas ao judiciário, à biomedicina e à saúde (SOUSA; AMARAL; SANTOS, 2019).

Esses trajetos desenham o intocável, o inacessível. Ao mesmo tempo em que as conjecturas sociais heterocentradas tentam inviabilizar e subalternizar mulheres trans e travestis, elas se reinventa na forma de experenciar/viver/existir a vida, mesmo sendo controladas por olhares epistêmicos e politicas mal admitidas, concentradas e colonizadas por uma heterossexualidade compulsória. Existe uma força estatal politica e histórica de apagamento desse multiverso. Trata-se de um modelo de sistema de analise liberal, branco, urbano, de classe média e euronorcentrado que não dialoga com frentes que tentem trazer para o ensejo os questionamentos das identidades e a necessidade que os movimentos tensionam e reivindicam enquanto politicas mais incisivas para a mudança. Tais movimentos vêm tentando mostrar como se encontra a situação sociopolítica e cultural dessa realidade, em contextos geopolíticos e com necessidades transespecífícas.

A despatologização foi um relevante passo. Entretanto, a transexualidade ainda consta no CD-11 como condição relativa à saúde mental, algo que precisa ser criticamente revisado e discutido, em especial pelos movimentos sociais trans e travestis e a rede de saúde. Dentro desse aspecto, existe a necessidade de se pensar categorias nosográficas dessa incongruência de gênero na infância, na adolescência e na fase adulta, precisando-se descolonizar o pensamento cisgênero no modelo de saúde e efetuar politicas que capacitem e preparem as 
pessoas que trabalham nas redes ligadas ao Estado, sejam na saúde, na assistência social e ou no campo educacional.

Carla, de 31 anos, travesti branca, residente na cidade de São Vicente, com pais professores e de classe média, resumiu bem todo esse desfecho que sustento aqui no artigo. Há a necessidade de intercambiar horizontes mais efetivos às questões de acesso, proteção, promoção, alcance e avanços dos direitos sexuais:

[...] o corpo é meu, faço o que quiser; e o SUS deveria ter obrigação ajudar, num é pra todos? [...] Quando a família ajuda, é maravilhoso, eu tive essa sorte, quando não, a fofoca, os olhares na esquina, o medo de sair de casa, as roupas, as unhas pintadas, te mata, e quando você vai buscar ajuda no bendito SUS, infelizmente, e olhe que já melhorou, morre novamente".

\section{Referências}

BRAH, Avtar. Diferença, diversidade, diferenciação. Cad. Pagu, Campinas , n. 26, p. 329376, jun. 2006.

BRASIL. Lei $\quad \mathrm{n}^{\circ} 1.521$, de 26 de dezembro de 1951. Disponível em: <http://www.planalto.gov.br/ccivil_03/leis/11521.htm>. Acesso em 15 mai. 2020.

BENTO, Berenice. "Da transexualidade oficial às transexualidades". In PISCITELLI, Adriana; GREGORI, Maria Filomena e CARRARA, Sérgio (orgs.), Sexualidade e saberes: convenções e fronteiras. Rio de Janeiro, Garamond, pp. 143-172, 2004.

BENTO, Berenice. A reinvenção do corpo: sexualidade e gênero na experiência transexual. Rio de Janeiro, Garamond, 2006.

A distinção: critica social do julgamento. São Paulo/Porto Alegre,

Edusp/Zouk, 2007.

BUTLER, Judith. Problemas de gênero. Rio de Janeiro: Civilização Brasileira, 2003.

Cuerpos que importan. Buenos Aires: Paidós, 2008.

. "Performatividad, precariedad y politicas sexuales". AIBR: Revista de Antropología Iberoamericana, n.3, 4: p.321-336, 2009.

BRITO, C. P. “Já é negro e ainda quer ser travesti?” - Experiências trans de mulheres negras. Dissertação de mestrado, Universidade Estadual do Sudoeste da Bahia, Jequié, BA, Brasil, 2006. 
CORRÊA, M. Repensando a família patriarcal brasileira. In: CORRÊA, M. et alii. Colcha de retalhos - estudos sobre família no Brasil. Campinas, Ed. Unicamp, 1994, pp.5-16.

CSORDAS, Thomas. (1990). “Embodiment as a Paradigm for Anthropology”. Ethos, v.18: p. $5-47$.

"A Corporeidade como um Paradigma para a Antropologia". Corpo, significado, cura. Porto Alegre: Editora UFRGS, 2008.

- "Fenomenologia cultural corporeidade: agência, diferença sexual, e doença”. Educação (Porto Alegre, impresso), v. 36, n. 3, pp. 292-305, set./dez, 2013.

Dossiê̂ dos assassinatos e da violência contra travestis e transexuais brasileiras em 2019 / Bruna G. Benevides, Sayonara Naider Bonfim Nogueira (Orgs). - São Paulo: Expressão Popular, ANTRA, IBTE, 2020.

FOUCAULT, M. História da Sexualidade, vol. I - A vontade de saber. Rio de Janeiro, Graal, 1982.

GARCÍA, Andrea. "Tacones, siliconas, hormonas. Teoría feminista y experiencias trans en Bogotá". Tesis para optar el grado de de Magister en Estudios de Género. Bogotá:Universidad Nacional de Colombia, 2018.

GILliAM, Angela; GILLIAM, Onik'a. Negociando a Subjetividade de Mulata no Brasil. Revista Estudos Feministas, Florianópolis, v. 3, n. 2, p. 525, jan. 1995. ISSN 1806-9584. Disponível em: <https://periodicos.ufsc.br/index.php/ref/article/view/16471>. Acesso em: 07 jan. 2020.

GUPTA, A.; FERGUSON, J. Mais Além da Cultura: espaço, identidade e política da diferença. In: ARANTES, A. (Org.) O Espaço da Diferença. Campinas: Papirus, 2000. pp. $30-49$.

HOOKS, Bell. Intelectuais negras. Tradução de Marcos Santarrita. Estudos feministas,Florianópolis, v. 3, n.2, p. 464-478, ago./dez. 2005.

KULICK, Don. Travesti - prostituição, sexo, gênero e cultura no Brasil. Rio de Janeiro: Editora Fiocruz; 2008. 280 p.

MACHADO, L. Perspectivas em confronto: relações de gênero ou patriarcado contemporâneo? Série Antropologia, UnB, Brasília, 2000.

MORA, Claudia; FRANCH, Monica; MAKSUD, Ivia; RIOS, Luis Felipe. Apresentação Dossiê - HIV/AIDS: sexualidades, subjetividades e politicas. REVISTA LATINOAMERICANA, n. 30 - dic, p.141-152, 2018.

MORAWSKA, Catarina. Vozes da Diferença: tempo e transformação entre educadores populares em Pernambuco. ILHA - v. 19, n. 2, p. 213-244, dezembro de 2017. 
NASCIMENTO, S.S. Homem com homem, mulher com mulher: paródias sertanejas no interior de Goiás. cadernos Pagu (39), julho-dezembro de 2012:367-402.

"Variações do feminino: circuitos do universo trans na Paraíba".

Revista de Antropologia, São Paulo, USP, v. 57 no 2, 2014.

- Fugas e contrapontos na fronteira: reflexões etnográficas sobre transitividades corporais e de gênero no Alto Solimões/AM. Revista antropologia da UFSCAR, 11 (1), jan./jun. 2019: 524-551.

SILVA, Hélio R. Travesti - A invenção do Feminino. Rio de Janeiro: Relume Dumará/ ISER, 1993.

TAUSSIG, Michael. Mimesis and alterity - a particular history of senses. Nova Iorque, Routledge, 1993.

TOTA, Martinho. Cinco Vidas: travestilidade, gênero, sexualidades e etnicidades no interior da Paraíba. REVISTA DE ANTROPOLOGIA, p. 173 - 207, 2015.

PELÚCIO, Larissa. "Na noite nem todos os gatos são pardos: notas sobre prostituição travesti”. Cadernos Pagu, n. 25: 217-248, 2005.

Nos nervos, na carne, na pele : uma etnografia sobre prostituição travesti e o modelo preventivo de AIDS - São Carlos : UFSCar, 2007. 312 p.

Abjeção e desejo - uma etnografia travesti sobre o modelo preventivo da Aids. São Paulo, Annablume/Fapesp, 2009.

PINHEIRO, Tarcísio Dunga; MAIA, Igor Fidelis. DOS ESTUDOS FEMINISTAS ÀS EXPERIÊNCIAS TRANS: Contribuições Teórico-Científicas Dos Estudos De Gênero Para A Proeminência Das Vivências Trans. Cronos: Revista da Pós-Grad. em Ciências Sociais, UFRN, Natal, v. 20, n. 1, jan./jun. 2019, ISSN 1982-5560.

PISCITELLI, Adriana. Interseccionalidades, categorias de articulação e experiências de migrantes brasileiras. Sociedade e Cultura, Goiânia, vol.11, no 2, jul./dez 2008, pp.263-274.

Atravessando fronteiras: teorias pós-coloniais e leituras antropológicas sobre feminismos, gênero e mercados do sexo no Brasil. Contemporânea, São Carlos, v. 3, n.2, p. 377-404, 2013.

PINHO, Osmundo. "Putaria": masculinidade, negritude e desejo no pagode baiano. Maguaré. v. 29, n. 02, 2015, pp. 209-238.

REVOREDO, Marisol Fernández. Identidades trans, interseccionalidad y las políticas públicas en el Perú. Preparado para presentar en el congreso virtual LASA 2020 de la Asociación de Estudios Latinoamericanos del 13 al 16 de marzo de 2020. 
SEFFNER, F. \& PARKER, R. "Desperdício da experiência e precarização da vida: momento político contemporâneo da resposta brasileira à aids". Interface. No. 20, p. 293-304, 2016.

SOUSA, E.T; AMARAL, M.S; SANTOS, D.K. Atuação do GT gênero e sexualidades do CRP-SC: enfrentamentos à lógica patologizante diante de interpelações (cis)normativas. IN: SOUSA, E.T; AMARAL, M.S; SANTOS, D.K. (Org.) Psicologia, travestilidades e transexualidades : compromissos ético-políticos da despatologização Florianópolis: Tribo da Ilha, 2019.

OLIVEIRA, Megg Rayara Gomes de. "Por que você não me abraça? Reflexões a respeito da invisibilização de travestis e mulheres transexuais no movimento social de negras e negros". Disponível em: <https:// sur.conectas.org/wp-content/uploads/2019/05/sur-28-portuguesmegg-rayara-gomes-de-oliveira. pdf> . Acesso em 15 mai. 2020 